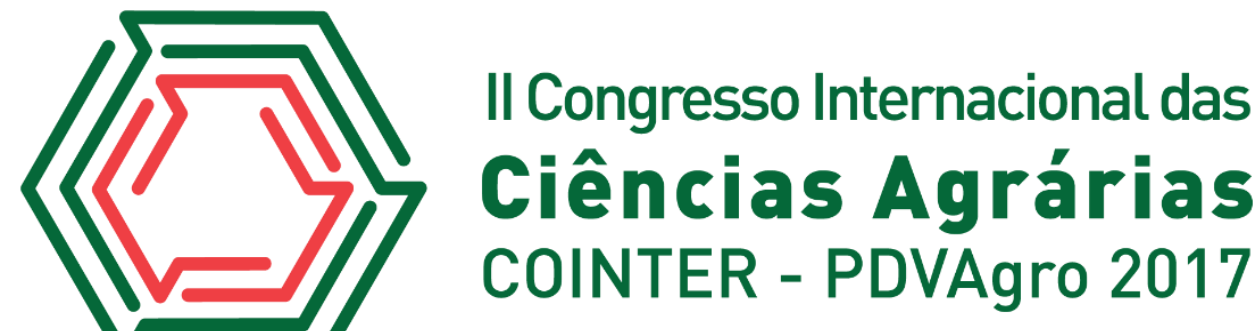

\section{EFEITO DE CONDIMENTOS NA QUALIDADE MICROBIOLÓGICA DA CARNE CAPRINA}

Apresentação: Pôster

\begin{abstract}
Maria Érica da Silva Oliveira ${ }^{1}$; Jéssica Taiomara Moura Costa Bezerra de Oliveira ${ }^{2}$; Keliane da Silva Maia ${ }^{3}$; Maria Carla da Silva Campêlo ${ }^{4}$; Patrícia de Oliveira Lima ${ }^{5}$
\end{abstract}

\section{Introdução}

A comercialização de alimentos em feiras livres é uma cultura antiga e os consumidores acreditam que comprar nesses locais obtém-se produtos frescos e com melhor qualidade. Entretanto, a manipulação e as condições em que alguns alimentos são comercializados muitas vezes não são adequadas e não se sabe de que maneira o alimento foi adquirido (FREITAS et al., 2015).

Nas últimas décadas, a preocupação do consumidor em adquirir alimentos seguros e mais naturais vem aumentado. A boa qualidade higiênico-sanitária diminui a incidência de doenças transmitidas por alimentos e garante que se tenha uma alimentação mais saudável (ALBUQUERQUE et al., 2009). Métodos de conservação podem ser aplicados para garantir a segurança do alimento, como por exemplo, o uso de aditivos naturais com propriedades antimicrobianas. Segundo Tajkarimi et al. (2010), a utilização de especiarias, frutos e óleos essenciais com ação antimicrobiana podem ser utilizados para garantir a segurança e a conservação de alimentos.

Tendo em vista a grande comercialização de carnes em feiras livres, muitas vezes em condições precárias de segurança e higiene, e a crescente procura por alimentos seguros e naturais, objetivou-se com essa pesquisa avaliar as condições microbiológicas e o efeito de aditivos naturais em carne caprina adquirida em feira livre da cidade de Mossoró/RN.

\section{Fundamentação Teórica}

A carne, alimento muito comercializado em feiras livres, é um meio de cultura ideal para o crescimento de micro-organismos. Quando as condições higiênicas do ambiente e dos manipuladores são precárias e quando os métodos de conservação são inadequados, há uma maior contribuição para a redução da vida útil do produto (PARDI et al, 2006; OLIVEIRA et al., 2008).

\footnotetext{
${ }^{1}$ Mestrado em Ciência Animal, UFERSA, erikinhaoliver10@yahoo.com.br

${ }^{2}$ Mestrado em Ciência Animal, UFERSA, j.taiomara@ hotmail.com

${ }^{3}$ Doutorado em Ciência Animal, UFERSA, kelianemaia@gmail.com

${ }^{4}$ Doutorado em Ciência Animal, UFERSA, carlacampelo2@ hotmail.com

${ }^{5}$ Doutora em Zootecnia, Docente na Universidade Federal Rural do Semiárido, UFERSA, pattlima@ufersa.edu.br
} 
Sendo a carne um alimento altamente perecível, é necessário que métodos de conservação sejam utilizados (FRITZEN et al., 2006; JAY, 2005; LUNDGREN, 2009).

Com as modificações na fabricação, comercialização e distribuição dos alimentos que ocorreram nas últimas décadas, o aparecimento e o uso de aditivos foi um importante recurso no processo de conservação, associado a novas técnicas, controle de matéria-prima e do produto acabado, uso de embalagens, dentre outros processos básicos (AISSA, 2010; EVANGELISTA, 2008). A sua inclusão trouxe a vantagem da preservação das características dos alimentos por um longo tempo, bem como a melhoria das propriedades organolépticas. Com isso, o uso dos aditivos alimentares se tornou potencialmente indispensável (ALBUQUERQUE, et al., 2012; GOUVEIA, 2006). Garantir a segurança e, ao mesmo tempo, atender a demanda para a conservação de atributos nutricionais e de qualidade têm resultado na crescente busca de conservantes naturais com potencial aplicação em alimentos, que possam ser utilizados sozinhos ou em combinação com outra tecnologia (SETTANNI; CORSETTI, 2008). A necessidade tecnológica do uso de um aditivo deve ser justificada sempre que proporcionar vantagens na tecnologia de fabricação, na conservação e nas características sensoriais (BRASIL, 1997).

\section{Metodologia}

Para a realização da pesquisa, foi utilizada carne caprina proveniente de uma feira livre da cidade de Mossoró/RN. As amostras foram adequadamente acondicionadas e conduzidas ao Laboratório de Análises Instrumentais e Sensoriais (UFERSA). A amostra de carne foi dividida em 3 pesos iguais e distribuídos em: um Controle (carne in natura sem adição de tempero); T1 (carne adicionada de tempero comercial) e T2 (carne adicionada de tempero natural à base de abacaxi).

O tempero comercial foi adquirido no comércio local da cidade de Mossoró-RN. Foi elaborado um tempero natural a base de abacaxi, composto pelos seguintes ingredientes: Suco de abacaxi, na proporção de 1:1 (água + polpa); vinagre; alho; canela em pó; cebola; cravo da índia; gengibre em pó; pimenta do reino e sal. Os cortes foram submetidos ao processo de imersão nas devidas soluções de tempero, utilizando a proporção tempero:carne de 2:1 (v/p), por um período de seis horas. Após o tempo de imersão, foi feita a drenagem por 5 minutos e após esse tempo, as amostras foram armazenadas sob refrigeração a $5^{\circ} \mathrm{C}$ por 12 horas até a realização das análises microbiológicas. As análises microbiológicas foram realizadas no Laboratório de Inspeção de Produtos de Origem Animal (UFERSA). As amostras foram submetidas às análises dos seguintes micro-organismos: Mesófilos, Psicrotróficos, Staphylococcus, Coliformes fecais e Escherichia coli. Tais análises foram realizadas de acordo com o que preconiza a Instrução Normativa $\mathrm{N}^{\circ} 62$, de 26 
de agosto de 2003 (BRASIL, 2003). Os resultados das análises foram submetidas a Teste de comparação de média de Tukey, a nível de probabilidade de $5 \%(\mathrm{p}<0,05)$, utilizando o programa SISVAR, versão 4.2 (FERREIRA, 2003).

\section{Resultados e Discussões}

A Tabela 1 sumariza os valores médios dos resultados de mesófilos, psicrófilos, Staphylococcus, coliformes fecais e Escherichia coli encontrados para cada micro-organismos nos tratamentos.

Tabela 1 - Valores obtidos para a contagem de microrganismos mesófilos, psicrófilos, Staphylococcus, coliformes fecais e

\begin{tabular}{lccc}
\multicolumn{4}{c}{ Escherichia coli. } \\
\hline \multicolumn{1}{c}{ Micro-organismos } & Controle & $\mathrm{T} 1$ & $\mathrm{~T} 2$ \\
\hline Mesófilos (UFC/g) & $2,5 \times 10^{6} \mathrm{a}$ & $2,5 \times 10^{6} \mathrm{a}$ & $2,5 \times 10^{6} \mathrm{a}$ \\
Psicrotróficos (UFC/g) & $3,35 \times 10^{5} \mathrm{a}$ & $1,25 \times 10^{4} \mathrm{~b}$ & $2,5 \times 10^{3} \mathrm{c}$ \\
Staphylococcus (UFC/g) & $2,0 \times 10^{6} \mathrm{a}$ & $2,0 \times 10^{6} \mathrm{a}$ & $3,1 \times 10^{5} \mathrm{~b}$ \\
Coliformes totais (UFC/g) & $1,01 \times 10^{6} \mathrm{~b}$ & $1,50 \times 10^{6} \mathrm{a}$ & $6,6 \times 10^{5} \mathrm{c}$ \\
Escherichia coli (UFC/g) & $3,9 \times 10^{5} \mathrm{~b}$ & $4,8 \times 10^{5} \mathrm{a}$ & $2,1 \times 10^{5} \mathrm{c}$ \\
\hline
\end{tabular}

Valores com letras sobrescritas iguais, em uma mesma linha, não diferem estatisticamente ao nível de 5\% pelo teste de Tukey. Controle (Carne in natura); T1 (Tempero comercial); T2 Tempero Natural a base de abacaxi).

Em relação aos resultados para mesófilos, observou-se que não houve diferença significativa entre os tratamentos. Como a contagem de mesófilos é comumente empregada para indicar a qualidade sanitária dos alimentos, podemos constatar que a presença elevada desses microorganismos nas amostras pode estar relacionada com as condições higiênico-sanitárias deficientes da carne in natura (FRANCO; LANDGRAF, 2008). Falhas no processo de abate dos animais ou nas condições higiênicas durante a manipulação podem ter interferido na qualidade microbiológica da carne. Observou-se que com o tratamento T2 houve redução da contagem dos micro-organismos psicrófilos, Staphylococcus, coliformes fecais e Escherichia coli. Em relação à contagem de psicotróficos, observou-se que houve diferença significativa entre todos os tratamentos, verificandose que a utilização do tempero natural a base de abacaxi tem a capacidade de prolongar o período de conservação da carne refrigerada $\left(0^{\circ} \mathrm{C}\right.$ e $\left.7^{\circ} \mathrm{C}\right)$. Observou-se que o tratamento $\mathrm{T} 2$ diminuiu a contagem de Staphylococcus. Apesar dessa diminuição, todas amostras apresentaram quantidades de Staphylococcus superior ao permitido pela legislação brasileira, que limita em até $5 \times 10^{3} \mathrm{UFC} / \mathrm{g}$ em produtos cárneos refrigerados para comercialização (BRASIL, 2001). Moura et al. (2006) justificam uma alta população de Staphylococcus por conta da manipulação inadequada da carne durante toda a cadeia de processamento.

Quanto à contagem de Coliformes totais, verificou-se que esses micro-organismos estavam acima do limite estabelecido pela legislação, que estabelece o máximo de $10^{4} \mathrm{UFC} / \mathrm{g}$ em carne 
refrigerada (BRASIL, 2001). Entretanto, ao comparar os tratamentos, observou-se que T2 diferiu significativamente dos demais, sendo o mais efetivo na redução desses micro-organismos. Em relação à contagem de Escherichia coli, verificou-se que houve diferença significativa entre os três tratamentos, sendo o tratamento T2 o mais efetivo. Escherichia coli é o principal representante do grupo dos coliformes totais, sendo indicador de contaminação fecal e da maioria das espécies de sangue quente (FRANCO; LANDGRAF, 2008). O aumento na contagem de Coliformes totais e Escherichia coli observado no tratamento T1 em relação ao Controle pode estar relacionado a uma possível contaminação do tempero comercial. Entre os fatores que podem ter contribuído para a maior eficácia do tratamento $\mathrm{T} 2$, podemos citar o $\mathrm{pH}$, visto que a proliferação de micro-organismos é diminuída em pH ácido (JAY, 2005). O abacaxi possui pH em torno de 3,5 a 4,0, além disso, o tempero contém ácidos cítrico e málico e ácido acético (NEVES, 2009). Outro fator contribuinte pode estar relacionado à presença de condimentos, como cravo e alho, contidos no tempero natural, por terem propriedades antimicrobianas (FRANCO; LANDGRAF, 2008).

\section{Conclusões}

$\mathrm{O}$ efeito do tempero natural à base de abacaxi foi eficiente na redução destes agentes contaminantes, demonstrando eficiente efeito antimicrobiano.

\section{Referências}

AISSA, A. F. Avaliação da atividade antimutagênica do beta-caroteno microencapsulado em células de ratos tratados com o antitumoral doxorrubicina empregado os ensaios de micronúcleo e cometa. 2010. 103f. Dissertação (Mestrado). Faculdade de Ciências Farmacêuticas de Ribeirão Preto, Universidade de São Paulo, Ribeirão Preto, 2010.

AlbuQuERQUE, M. V.; SANTOS, S. A. CERQUEIRA, N. T. V. SILVA, J. A. Educação alimentar: uma proposta de redução do consumo de aditivos alimentares. Química Nova na Escola, v. 34, n. 2, p. 51-57, 2012.

ALBUQUERQUE, R. B.; SOUZA, E. L.; STAMFORD, T. L. M.; STAMFORD, T. C. M. Perspectiva e potencial aplicação de quitosana como inibidor de Listeria monocytogenes em produtos cárneos. Revista Iberoamericana de Polímeros, v. 10, n. 5, p. 260-274, 2009.

BRASIL. Agência Nacional de Vigilância Sanitária. Resolução RDC nº 12, de 2 de janeiro de 2001. Aprovar o Regulamento Técnico sobre Padrões Microbiológicos para Alimentos. Diário Oficial da República Federativa do Brasil, Brasília, DF, 10 jan. 2001.

BRASIL. Instrução Normativa N $N^{\circ}$ 62, DE 26 DE AGOSTO DE 2003. Oficializa os Métodos Analíticos Oficiais para Análises Microbiológicas para Controle de Produtos de Origem Animal e Água. Diário Oficial da União, Brasília, DF, 18 set. 2003. 
BRASIL. Portaria $n^{\circ} 540$, de 27 de outubro de 1997. Aprova o Regulamento Técnico: Aditivos Alimentares - definições, classificação e emprego. Diário Oficial da União, Brasília, DF, 28 out. 1997.

EVANGELISTA, J. Tecnologia de Alimentos. $2^{\mathrm{a}}$ ed. São Paulo: Atheneu, 2008, 652p.

FERREIRA, D. F. SISVAR versão 4.2. Lavras, Universidade Federal de Lavras, 2003.

FRANCO, B. D. G. M.; LANDGRAF, M. Microbiologia dos alimentos. São Paulo: Atheneu, 2008, p. 182.

FREITAS, A. K. N.; FREIRE, L. DA S.; PAZ, H. C.; PIRES, R. M. C. Condições higiênicosanitárias de gêneros alimentícios comercializados no Mercado Central São José em Teresina-PI. Anais do $5^{\circ}$ Simpósio de Segurança Alimentar [recurso eletrônico], 26 a 29 de maio de 2015. Bento Gonçalves: SBCTA Regional, RS, 2015.

FRITZEN, A. L.; SCWERZ, D. L.; BABIATTI, E. C.; PADILHA, V.; MACARI, S. M. Análise microbiológica de carne moída de açougues pertencentes a $9^{\circ}$ regional de saúde do paraná. Higiene Alimentar, São Paulo, v. 20, n.144, p.81-83, 2006.

GOUVEIA, F. Indústria de alimentos: no caminho da inovação e de novos produtos. Inovação Uniemp [online], v. 2, n. 5, p. 32-37. 2006,

LUNDGREN, P. U.; SILVA, J. A.; MACIEL, J. F.; FERNANDES, T. M. Profile of the hygienicsanitary quality of bovine meat marketed at free markets and public markets of João Pessoa/PBBrasil. Alimentos e Nutrição, v.20, n. 1, p. 113-119, jan./mar. 2009.

MOURA, A. P. B. L.; ACIOLLI, R.; DUARTE, D. A. M; PINHEIRO JUNIOR, J. W.; ALCÂNTARA, J. S.; MOTA, R. A. Caracterização e perfil de sensibilidade Staphylococcus spp. isolados em amostras de carne caprina comercializadas em mercado e supermercados em Recife, PE. Arquivos do Instituto Biológico. São Paulo. v. 73, n. 1, p. 7-15. jan-mar, 2006.

NEVES, L. C. Manual pós-colheita da fruticultura brasileira. Londrina, PR: EDUEL, 2009. 494p.

PARDI, M. C.; SANTOS, I. F.; SOUZA, E. R.; PARDI, H. S. Ciência, higiene e tecnologia da carne. $2^{\mathrm{a}}$ ed. Goiânia, UFG, 2006, 623p.

JAY, J M. Microbiologia de alimentos. 6. ed. Porto Alegre, RS: Artmed, 2005. 711 p.

OLIVEIRA, R. B. A.; ROLIM, M. B. Q.; MOURA, A. P. B. L.; MOTA, R. A. Avaliação higiênicosanitária dos boxes que comercializam carnes. Medicina Veterinária, Recife, v. 2, n. 4, p. 10-16, 2008.

SETTANNI, L.; CORSETTI, A. Application of bacteriocins in vegetable food biopreservation. International Journal of Food Microbiology, v.121, n.2, p.123-138, 2008.

TAJKARIMI, M. M.; IBRAHIM, S. A.; CLIVER, D.O. Antimicrobial herb and spice compounds in food. Food Control, v. 21, n. 9, p. 1199-1218, 2010. 